\title{
Space Syntax's Relation to Seating Choices from an Evolutionary Approach
}

\author{
Barbara Keszei ${ }^{1,2,3^{*}}$, Bálint Halász ${ }^{4}$, Anna Losonczi ${ }^{4}$, Andrea Dúll ${ }^{3,5}$ \\ ${ }^{1}$ Doctoral School of Psychology, ELTE Eötvös Loránd University, Budapest, H-1064 Budapest, Izabella str. 46., Hungary \\ 2 Department of Pedagogy, Faculty of Commerce, Hospitality and Tourism, Budapest Business School, \\ H-1054 Budapest, Alkotmány str. 9., Hungary \\ ${ }^{3}$ Institute of Psychology, ELTE Eötvös Loránd University, Budapest, H-1064 Budapest, Izabella str. 46., Hungary \\ ${ }^{4}$ Ginkgo Architects, Budapest, Hungary, H-1114 Budapest, Dávid Ferenc str. 11., Hungary \\ ${ }^{5}$ Department of Sociology and Communication, Faculty of Economic and Social Sciences, Budapest University of Technology and \\ Economics, H-1111 Budapest, Egry József str. 11, Hungary \\ * Corresponding author, e-mail: keszei.barbara@uni-bge.hu
}

Received: 22 April 2019, Accepted: 31 October 2019, Published online: 28 November 2019

\begin{abstract}
Space syntax provides information on the probabilities of certain behaviour types (e.g., seating choice, movement) depending on the configuration of space. The evolutionary approach (e.g. Appleton's prospect-refuge theory) in environmental psychology can help designers in creating spaces by providing a better understanding why certain parts of an open space or a building are avoided or occupied, why good "observation points" or "hiding places" are preferred. Our research aimed to explore how different space syntax variables predict specific behaviours - the seating choices of 216 participants - in a 3D virtual model of a lounge area and how the prospect-refuge theory relates to these predictions. The participants had to choose a seat in simulated spaces in two social situations, which differed in the degree of focused work and concentration: one of the situations implied seeing others and being seen, while the other highlighted focused work and hiding. The results show that there was a variation in the seating choices depending on the goal of the situation (user: trying to be seen or hiding). The expected significant correlations with the space syntax measurements were presented in the situations where being seen was the goal of the participants. However, in the situations where hiding was induced, our results need further clarification. Our future goal is to provide quantitative, evidence-based reflection on the prospect-refuge and space syntax theories, and to investigate the psychological factors (e.g., goal of the user) that need further consideration when applying these theories in the design practice.
\end{abstract}

Keywords

space syntax, prospect-refuge theory, environmental psychology, prediction of behaviour

\section{Introduction}

Understanding human behaviour and affection is an important skill for designers creating places that are both aesthetically pleasing and functional. Designing more human-centred built environments can contribute to a person-environment fit (Kaplan, 1983; Edwards et al., 1998), which can have positive effects such as residential satisfaction (Kahana et al., 2003), better performance, and overall well-being at the workplace (Ostroff and Schulte, 2007).

The present study focuses on comparing and reconciling two approaches that aim to understand and predict human spatial behaviour: space syntax and evolutionary environmental psychology. Space syntax focuses on the relationship between the geometrical properties of the environment and the behaviour of the users of a certain space (Hillier and Hanson, 1984); while the evolutionary approach in psychology concentrates on the connection between the adaptation value of certain behaviours and preferences, including spatial behaviours and preferences (Buss, 2015).

Space syntax theory provides a powerful functional inventory to analyse the environment (Hillier and Hanson, 1984) but offers little insight into the causes of different behaviours. To understand these behaviours, Appleton's (1975) prospect-refuge theory is appropriate, because it focuses on the explanations of behaviours and furthermore, their connections to environmental features. This 
paper explores the application of space syntax theory by gathering evidence of different behavioural patterns and by exploring how these patterns can be explained through the lens of Appleton's theory.

\section{Evolutionary approach prospect-refuge theory}

Evolutionary approach in psychology explains behaviour, mental and psychological traits from the perspective of adaptation: how a certain behaviour helps survival or success to procreate (Buss, 2015).

An interesting question arises when narrowing down behaviour to spatial behaviour: why do people, in general, like or dislike, approach or avoid certain spaces, certain spatial situations? From an evolutionary perspective, avoiding dangerous spaces and developing an aesthetical dislike towards these places can be understood. In this regard, adaptive behaviour and preferences are bound together.

Multiple theories adopting the concept of evolutionary approach are related to spatial preferences (Appleton, 1975; Kaplan and Kaplan, 1982; Ulrich, 1983). In the present study, Appleton's (1975) prospect-refuge theory and its connections with space syntax approach is examined in detail.

Appleton's (1975) theory of prospect-refuge provides an explanation of preferences for landscape vistas, viewpoints, and certain spatial arrangements that are related to life-supporting environments.

Appleton identified elements of the environment that meet the needs for survival by being able "to see without being seen" (Appleton, 1975:p.73), while immediately experiencing an aesthetic satisfaction thanks to these environmental features.

Preferred spatial arrangements support seeing and hiding, and at the same time providing the opportunity for movement and exploration. Furthermore, Appleton emphasises the effect of the shade/sun duality and the "hazards" within the environment. Whether the "hazards" are real or imaginary, dangers are also a factor to be taken into account when assessing how safe a situation is, as well as the vicinity of it. Perceived risk can be exciting from a distance while being terrifying up close (Appleton, 1975).

Appleton's theory is widely used for assessing environments. However, it is worth noting that his theory was formulated based on natural environments and landscapes, and most of the studies applied it outdoors, in natural environments. While the significant role of prospect in spatial preference was proven in urban and indoor environments, the results were more neutral when testing refuge (Dosen and Ostwald, 2016). The importance of perceived brightness, lighting and shade might become more prevalent in interiors, compared to natural environments, in affecting feeling in refuge; consequently, for example, the colour of a painted wall could have an important role.

\section{Space syntax}

Space syntax theory is concerned with how social processes/relations impact space use and how these lead to the creation of certain spatial arrangements. It also examines the way the physical environment facilitates certain behaviours while rendering others difficult to take place (Bafna, 2003). Space syntax focuses on the geometrical and configurational logic of the space (Hillier, 1996), implying certain accessibilities and visibilities with ultimately different behavioural effects, apparent in patterns of space use (Hillier, 1996; Hillier and Penn, 1991) and social interaction (Hillier and Hanson, 1984; Peponis, 1985; Hillier, 1996; Kupritz, 2003). An integrated space is easily accessible and/or visually connected to other spaces within the environment (Behbahani et al., 2014); therefore, it might serve as a reasonable "vantage-point", a spot that offers prospect, and more control over the environment (Mumcu et al., 2010).

As an approach, space syntax mostly focuses on cityscale (Peponis et al., 1997; Jiang and Claramunt, 2002; Raford et al., 2007; Christova et al., 2012; Kádár, 2013) and large-scale environments, such as hospitals (Peponis et al., 1990; Haq and Luo, 2012); museums (Dursun, 2007; Hillier and Tzortzi, 2006); however, an increasing demand is apparent for studies in smaller-scale environments (Dosen and Ostwald, 2017; Psathiti and Sailer, 2017).

Commonly used measures of geometrical configurational quality in space syntax methodology are depth and visual integration. Depth is the necessity to go through intervening spaces to access that room (Hillier and Hanson, 1984), and visual integration is a normalised measure of visual distance from all other locations in the spatial system (Hillier and Hanson, 1984).

Observation is a method widely used in researching human spatial behaviour (Sussman, 2016; Ng, 2016), more specifically, observing spontaneous seating choices is used often in space syntax paradigm (Keskin et al., 2015; Psathiti and Sailer, 2017). Seating choices are assumed to reflect preferences, which can also be apparent in the behaviour of people in simulated environments. 


\section{Space syntax and prospect-refuge working in synergy} The collaboration of the two research fields of space syntax and the evolutionary approach in environmental psychology was addressed at the end of the 2000s (Montello, 2007). Nevertheless, papers have only been published on this specific topic in recent years (Haq and Girotto, 2003; Galindo and Hidalgo, 2005; Ostwald and Dawes, 2013; Dosen and Ostwald, 2016; Psathiti and Sailer, 2017).

Examining the relationship between prospect-refuge theory and space syntax is quite recent, and so far there is no clear evidence that the two theories can be combined and can strengthen each other in understanding the complex phenomenon of spatial behaviour (Ostwald and Dawes, 2013; Dawes and Ostwald, 2014; Dosen and Ostwald, 2013a; 2016; 2017; Psathiti and Sailer, 2017).

Different researchers tried to develop and expand their interpretations and definitions of the prospect-refuge theory, applying it to specific research questions and venues (Dosen and Ostwald, 2013a). The authors' previous study focused on finding an evidence-based connection between space syntax measurements and the openness for coincidental encounters, which was considered to be essential for interactions and developing creative ideas (Losonczi et al., 2017). Appleton's (1975) theory provided a new perspective and interpretation for the data, following the line of research converging on an understanding of behaviour from the perspective of prospect-refuge, while using the approach of space syntax to analyse spatial features.

\section{Research theme and hypothesis}

Our study relates tracked human spatial behaviours (seating choices of the experiment participants in a simulated environment) with space syntax variables that may predict certain aspects of behaviour, depending on the configuration and social function of space.

Space syntax theory focuses on geometrical variables, while non-geometry related variables are less within the scope of the theory. The study aimed to account for non-geometry related variables. It was assumed that non-geometry related variables would have a significant effect on behaviour besides the variables in the focus of space syntax.

It was expected that differences would be observed in seating preference patterns depending on the social situations the participants are put in. These social situations are defined by the type of social interactions the users are likely to engage in (Losonczi et al., 2017).
The study then aims to relate the observations with the types of spaces/environments and environmental responses that are in the centre of prospect-refuge theory.

The selected situations were separated into two groups based on Appleton's (1975) theory: prospect driven and refuge driven situations. Substantial differences in behaviours within the environment with the same space syntax index, depending on the social situations, were expected. Also, spatial behaviour would be affected by non-geometry related variables.

\section{Method}

The participants received the description of a research facility, where they had to imagine themselves working there as researchers. The case study environment (see detailed description below) was a researchers' lounge. The participants familiarised themselves within the environment via a GIF footage that mimicked a walk within a 3D virtual model of the environment. The participants read the description of a specific social-situation and had to choose a seat. Each participant was given four situations and had to choose a seat in each situation. The whole procedure was conducted online. The frequency of choices for each seat was used as an output variable in the subsequent statistical analysis.

\subsection{Environment}

The simulated case study environment was created for the present study based on the layout of the refurbished heritage building. The case study environment consisted of five rooms forming an L shape (see Fig. 1). The rooms were not divided by doors but by vaulted cuts in the dividing walls; therefore, the movement of the users was not obstructed.

In total, 72 seats were positioned in the five rooms (three seats around each table). The number of seats in the different rooms varied between two and six, depending on the size of the room (see Fig. 2).

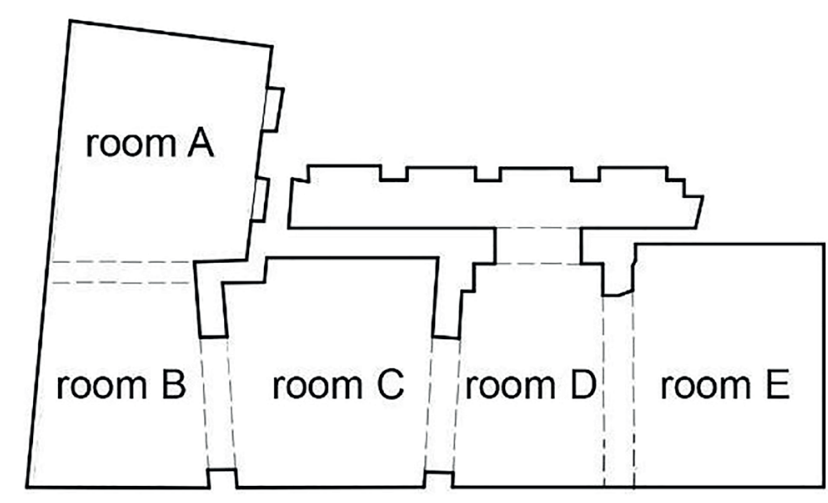

Fig. 1 Layout of the environment 


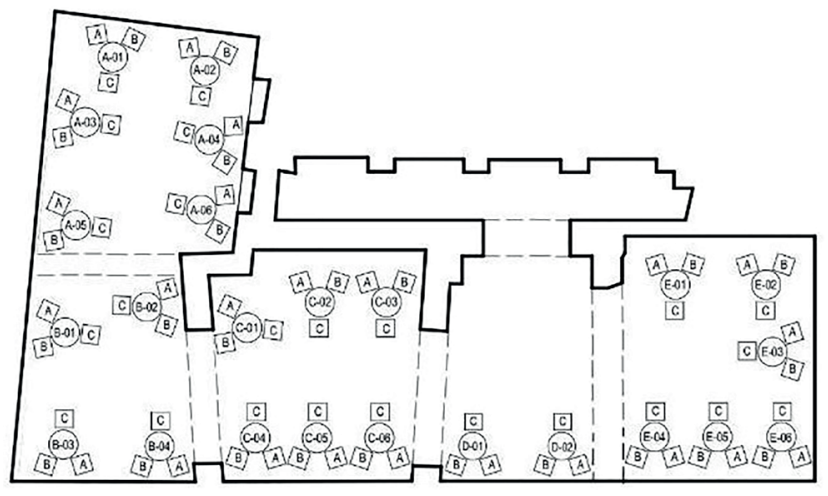

Fig. 2 Seats within the environment

During the research, spatial configuration remained unchanged; however, different variations of the non-configurational environmental features were used. Designensemble was introduced as a variable having two potential categories: GREEN and BLUE (See Figs. 3 and 4 respectively). The two design-ensembles varied only in the colours and materials applied. Architects were asked to design two design-ensembles and create them as distinct as possible but keep them lifelike, while leaving unchanged as many items of the interior as possible. The experiment was conducted by introducing the design-ensemble as a variable while another ongoing study is focusing on interpreting the effects of this specific variable. Although understanding the effects of the design-ensemble variable is outside the scope of this study, the results chapter includes differentiation by design-ensembles.

Another environmental variable used in the research was homogeneity, which variable was crossed with the design-ensemble variable. The homogeneity variable had two categories: homogeneous or heterogeneous environments, resulting in a total of four case study environments

In a homogeneous environment, all rooms have the same design ensemble (if all rooms are BLUE, it is called a homogeneousBLUE; if all are GREEN a homogeneousGREEN environment). In the heterogeneous environments, room $\mathrm{E}$ had the other type of design-ensemble (if room A, B, C and D were GREEN, then room E was BLUE, and the label heterogeneousGREEN was used, if all the rooms but room $\mathrm{E}$ were BLUE, the environment is called heterogeneousBLUE environment).

\subsection{Space syntax variables}

To capture multiple forms of integration, three measurements were used in the analysis, all related to the geometry of the space: total depth, intervisibility and visual

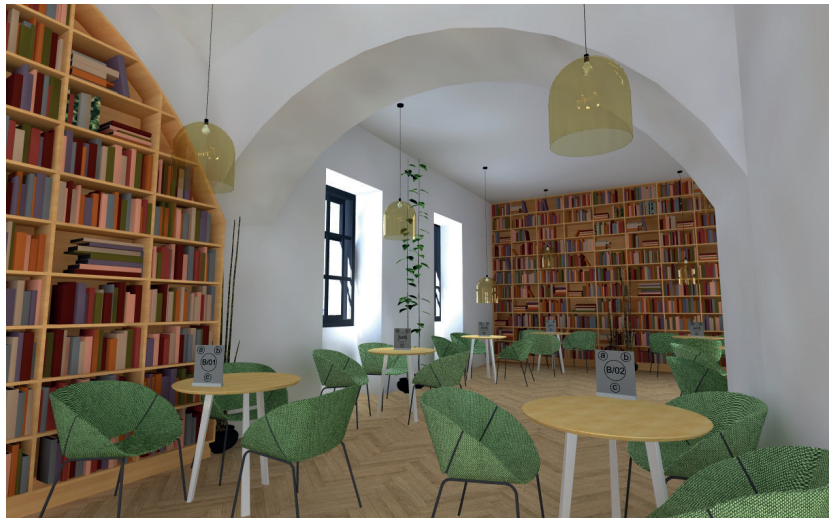

Fig. 3 The GREEN design-ensemble

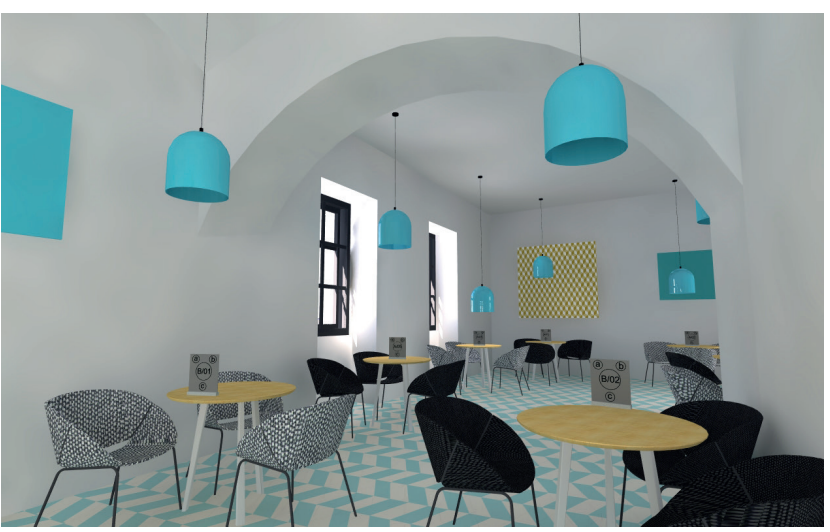

Fig. 4 The BLUE design-ensemble

integration. All the variables measure the integration of the space, that is how certain parts of the spatial arrangements have connections with other spaces in a spatial system (a hall with many entrances to different rooms) (Bafna, 2003).

\subsubsection{Total depth}

Depth and total depth are indexes that apply to the scale of a room. Depth is measurable between two rooms by counting the spaces/rooms between them. Total depth is calculated by summing all the possible depths in a given environment (Hillier and Hanson, 1984) (see Fig. 5). Compared to the following indexes, total depth measurements can be considered vague.

A higher level of total depth indicates that a certain room is not easily accessible; therefore, it might act as a potential hiding place.

\subsubsection{Intervisibility and visual integration}

Space syntax measurements such as intervisibility and visual integration were calculated with the software DepthmapX (Turner, 2004). The program creates a grid on the layout and uses the centres of the grids as points to run the graph analysis (Turner, 2004). 


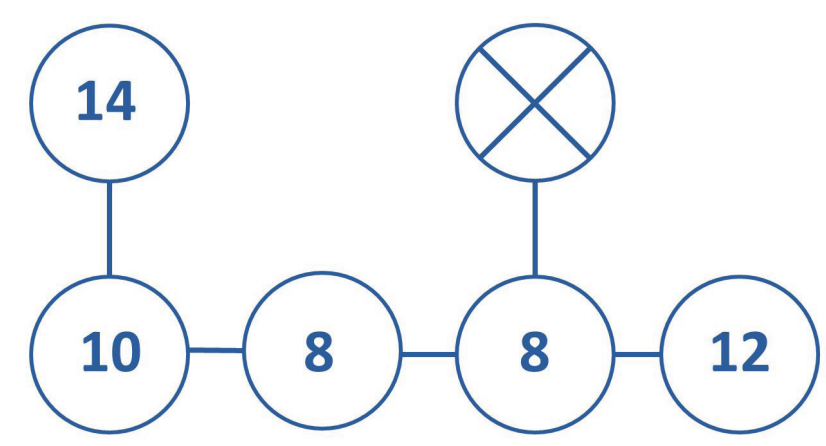

Fig. 5 The total depth graph of the layout

The intervisibility graph of the case study environment (see Fig. 6) shows the connectivity of each node, that is the number of locations that can be seen from each node, while the visual integration graph (see Fig. 7) shows the shortest paths from each node (grid) to all other nodes (Turner, 2004).

Higher levels of intervisibility and visual integration indicate that a certain space/field in the grid is easily accessible and connected to other spaces/fields; therefore, it might serve as a prospect.

\subsection{Social situations}

The respondents met the virtual environment in two different 'social situations'. The purpose of the situations was to give the respondents a believable setting: they had to imagine that they were researchers in a research facility and needed a change of scenery. So, they went to the researchers' lounge and had to choose where to sit down. The social situations varied in the amount of focused work the respondents needed to do. One situation sought to model and imitate settings when a person is looking for a place to hide (to be able to focus on work without being distracted by coincidental encounters, being less open to these coincidental encounters (Losonczi et al., 2017) without being seen). This situation will be called the prospect-demanding situation in the study.

The other situation imitated the goal of needing refuge within the environment. While in the other situation the goal in choosing a seat was to see and to be seen by co-workers in the researchers' lounge, being open to coincidental encounter (Losonczi et al., 2017). This situation corresponded to the goal of having a prospect within the environment; consequently, it is labelled in the study refuge-demanding situation.

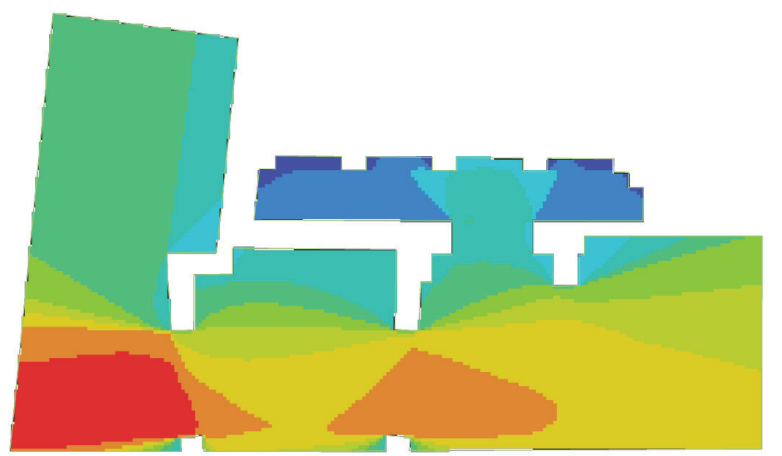

Fig. 6 The intervisibility graph of the layout

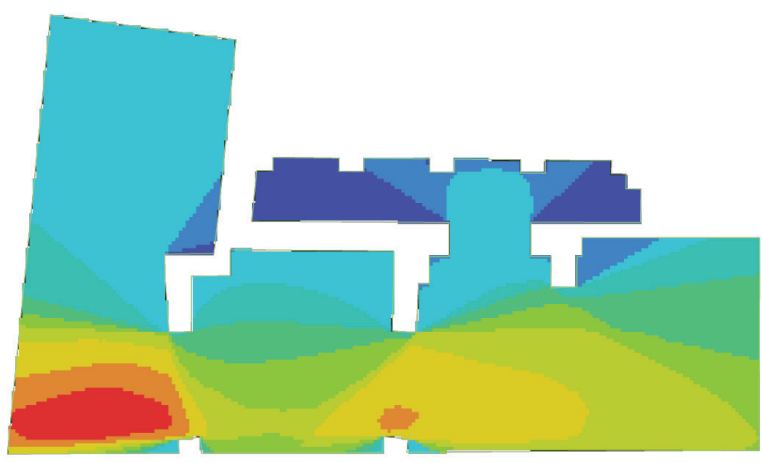

Fig. 7 The visual integration graph of the layout

\section{Results}

The study involved 216 adults (97 males and 119 females, 73 visual professionals, 143 laypeople; age 35.75 years, $\mathrm{SD}=10.36$, min. 19, max. 73). Convenience sampling was applied. Familiarity with 3D environments and immersion in the simulated environment was controlled, both receiving fairly high scores $3.66(\mathrm{SD}=1.3)$ and $4.09(\mathrm{SD}=0.75)$ respectively on a 5-point Likert-scale (one indicating less familiarity and less immersion).

The research analysed Pearson's correlations between the seating choice frequencies and the space syntax measurements. This helped in uncovering the connections between space syntax measurements and the prospect-refuge theory. Results of the correlations are shown in Table 1 in the two social situations, in the four different environments. SPSS 24 was used for the statistical analysis.

The prospect-demanding situation is considered to be more open to the stimuli of the environment, as seeing others was implied in the description of the situation. In this situation, the expectation was to have a higher seating choice frequency for the seats located in a visually integrated environment. Significant positive correlations 
Table 1 Correlations between seating choice frequencies and space syntax indexes

(two-sided $\mathrm{r}$ values are shown; $*$ is indicating $\mathrm{p}<0.05$; ** indicating $\mathrm{p}<0.01$ )

\begin{tabular}{|c|c|c|c|c|c|c|c|c|c|c|c|c|}
\hline \multirow[b]{2}{*}{ Situation } & \multicolumn{3}{|c|}{ homogeneousGREEN env. } & \multicolumn{3}{|c|}{ homogeneousBLUE env. } & \multicolumn{3}{|c|}{ heterogeneousGREEN) env. } & \multicolumn{3}{|c|}{ heterogeneousBLUE env. } \\
\hline & $\begin{array}{l}\text { Total } \\
\text { depth }\end{array}$ & $\begin{array}{l}\text { Intervis. } \\
\text { graph }\end{array}$ & $\begin{array}{l}\text { Visual } \\
\text { integr. }\end{array}$ & $\begin{array}{l}\text { Total } \\
\text { depth }\end{array}$ & $\begin{array}{l}\text { Intervis. } \\
\text { graph }\end{array}$ & $\begin{array}{l}\text { Visual } \\
\text { integr. }\end{array}$ & $\begin{array}{l}\text { Total } \\
\text { depth }\end{array}$ & $\begin{array}{l}\text { Intervis. } \\
\text { graph }\end{array}$ & $\begin{array}{l}\text { Visual } \\
\text { integr. }\end{array}$ & $\begin{array}{l}\text { Total } \\
\text { depth }\end{array}$ & $\begin{array}{l}\text { Intervis. } \\
\text { graph }\end{array}$ & $\begin{array}{l}\text { Visual } \\
\text { integr. }\end{array}$ \\
\hline $\begin{array}{l}\text { Prospect-demanding } \\
\text { situation }\end{array}$ & -0.070 & $0.345 * *$ & $0.369 * *$ & 0.003 & 0.164 & 0.183 & -0.057 & $0.351^{* *}$ & $0.381 * *$ & 0.037 & $0.236^{*}$ & $0.275^{*}$ \\
\hline $\begin{array}{l}\text { Refuge-demanding } \\
\text { situation }\end{array}$ & 0.075 & 0.033 & 0.081 & 0.174 & -0.002 & 0.024 & 0.047 & 0.157 & 0.205 & 0.122 & 0.019 & 0.035 \\
\hline
\end{tabular}

between seating choices, visual integration and intervisibility were expected, while with total depth significant negative correlations were predicted.

Total depth did not show the expected significant negative correlation with seating choices.

Significant positive correlations were found between seating choice and visual integration and intervisibility in the prospect-demanding situation in all environments except one (homogenousBLUE environment).

Regarding the prospect-demanding situation, our results show a slight inconsistency. While in $75 \%$ of the environments, the expected positive correlations with visual integration and intervisibility were found, these relationships were entirely missing in homogeneous BLUE environment. Regarding total depth, the expected negative correlation with seating preference did not appear. Total depth is a more vague measurement compared to intervisibility and visual integration, and this could cause these results by blurring the spatial differences relevant in the evaluation of prospect.

The refuge-demanding situation was deemed to be less open to the stimuli of the environment; being able to concentrate on work was the focal point of the description of the situation. In this situation, expectations posited by the study were opposite to those in the prospect-demanding situation.

In the less open situation - considered to be a refuge-demanding situation - the expected results were not found.

\section{Conclusion}

Appleton's (1975) prospect-refuge theory is well-known in environmental psychology, architecture, landscape planning and urban and interior design (Dosen and Ostwald, 2013a). However, little is known about the predictive power of the theory when observing behaviour, and inconsistent results can be found when investigating the evidence-based results (Dosen and Ostwald, 2016). To add to the evidence-based research related to the prospect-refuge theory in built and indoor environments, the case study environment was a simulated researchers' lounge located in a heritage building, therefore, providing a realistic layout.

During the research, two social situations were used: one of them accentuating the goal of prospect, one underlining refuge. A further research question was what kind of effect design-ensembles have on seating choices, on perceived prospect or refuge. To test this, four different design-environments were used (using two design-ensembles and their homogeneous or heterogeneous variations).

The results are aligned with the meta-analysis of Dosen and Ostwald (2016) who found that in interiors, the prospect aspect of prospect-refuge shows significant connection with preference. However, in the case of the refuge-demanding situation the results of seating choices in this study are more in the neutral zone. Presumably the "hazards" mentioned by Appleton (1975) are less relevant in indoor environments than in urban or natural sceneries, making the parallel presence of prospect and refuge in the same time in the same space unnecessary for the user of the space. In an already controlled environment, such as the researcher's lounge of a workplace in our study, safety might not be a pertinent factor, while prospect might be understood as an opportunity in such settings.

The correlations between space syntax measurements and seating choices were weak even in significant cases. The weak correlations are unlikely to be the consequence of the environment being simulated, as other studies showed that real-life environments might also produce mixed results and weak correlations (Psathiti and Sailer, 2017).

Space syntax measurements mostly take into account the layout of the place excluding other aspects of the environment such as the 3D features of the environment (cf. Varoudis and Psarra, 2014), ceiling height (cf. Dosen and Ostwald, 2013a), or the views from the windows (Dosen and Ostwald, 2013b). These factors can have an immense effect on feeling safe, having a refuge or having an overview, a prospect. 
An upcoming step in understanding the relationship between prospect-refuge theory, space syntax and predicting behaviour - especially in built environments - can be to use more refined space syntax measurements and using joint metrics (Psathiti and Sailer, 2017).

To better understand the results, qualitative research is necessary. As previously mentioned, the authors are investigating the effects of design-ensembles in an ongoing study. The possible interpretations, the connotative meanings of the different design-ensembles and their effects on seating choices or the perceived prospect or refuge are not in the scope of the present study.

It should be pointed out that even though the situations were meant to grasp the essence of prospect and refuge in a believable, relatable manner, the lack of significant correlations in refuge-demanding situation suggest that further investigation in the interpretation of the social situations is required, especially in the refuge-oriented social situation, although the lack of significant results could also show the general lack of connection between seating choices and environmental preferences with refuge in interiors (Dosen and Ostwald, 2016).

A limitation of the study is that the respondents reacted to an empty environment, without anybody being present in the researchers' lounge, which would not be a likely scenario in real life. Therefore, the behaviour might be different with people occupying the environment. Another limitation was that convenient sampling was used, and presumably, the upper-middle-class was overrepresented

\section{References}

Appleton, J. (1975) "The experience of landscape", John Wiley and Sons, London, UK.

Bafna, S. (2003) "Space Syntax: A Brief Introduction to Its Logic and Analytical Techniques", Environment and Behavior, 35(1), pp. 17-29. https://doi.org/10.1177/0013916502238863

Behbahani, P. A., Gu, N., Ostwald, M. J. (2014) "Comparing the properties of different space syntax techniques for analysing interiors", In: Madeo, F., Schnabel, M. A. (eds.) Across: Architectural Research through to Practice: 48th International Conference of the Architectural Science Association 2014, The Architectural Science Association \& Genova University Press, Genova, Italy, pp. 683-694. [online] Available at: http://anzasca.net/wp-content/ uploads/2014/12/14_54_81.pdf [Accessed: 25 March 2019]

Buss, D. M. (2015) "Evolutionary psychology: The new science of the mind", Psychology Press, Palmeira Mansions, Brighton, UK.

Christova, P., Scoppa, M., Peponis, J., Georgopoulos, A. P. (2012) "Exploring small city maps", Experimental Brain Research, 223(2), pp. 207-217.

https://doi.org/10.1007/s00221-012-3252-Z in our sample. Despite the limitations regarding the sampling, an asset of the study was that even though some university students appeared among the participants, the mean age (36 years) is higher than the university student age group.

The authors would like to emphasise the importance of the research having taken place in indoor environments with multiple rooms, which is rare in prospect-refuge studies (Dosen and Ostwald, 2016).

The future goal is to continue the multidisciplinary approach in research providing quantitative, evidence-based reflection on the prospect-refuge and space syntax theories, and to use qualitative methods in investigating the psychological factors (for example, goal of the user, the connotations of the different design elements) that have to be considered when applying these theories in the design practice.

\section{Acknowledgement}

This work was completed in the framework of the ELTE Institutional Excellence Program (783-3/2018/ FEKUTSRAT) supported by the Hungarian Ministry of Human Capacities.

The authors would like to thank the designer architects Anna Felcsúti, Lilla Turi, Attila Kurucz for assisting in the creation of the case study environments, Dániel Dobszai for his help in conducting the research, and the management of Ginkgo Architects for collaborating in the project.

Dawes, M. J., Ostwald, M. J. (2014) "Testing the 'Wright Space': using isovists to analyse prospect-refuge characteristics in Usonian architecture", The Journal of Architecture, 19(5), pp. 645-666. https://doi.org/10.1080/13602365.2014.965722

Dosen, A. S., Ostwald, M. J. (2013a) "Prospect and refuge theory: constructing a critical definition for architecture and design", The International Journal of Design in Society, 6(1), pp. 9-24. https://doi.org/10.18848/2325-1328/CGP/v06i01/38559

Dosen, A. S., Ostwald, M. J. (2013b) "Methodological characteristics of research testing prospect-refuge theory: a comparative analysis", Architectural Science Review, 56(3), pp. 232-241. https://doi.org/10.1080/00038628.2013.809689

Dosen, A. S., Ostwald, M. J. (2016) "Evidence for prospect-refuge theory: a meta-analysis of the findings of environmental preference research", City, Territory and Architecture, 3, Article number: 4. https://doi.org/10.1186/s40410-016-0033-1

Dosen, A. S., Ostwald, M. J. (2017) "Lived space and geometric space: comparing people's perceptions of spatial enclosure and exposure with metric room properties and isovist measures", Architectural Science Review, 60(1), pp. 62-77. https://doi.org/10.1080/00038628.2016.1235545 
Dursun, P. (2007) "Space Syntax in Architectural Design", In: 6th International Space Syntax Symposium, Istanbul, Turkey, pp. 0561-056-12. [online] Available at: https://www.researchgate.net/ profile/Pelin_Dursun/publication/228646158_Space_Syntax_in_ Architectural_Design/links/54a696690cf257a6360a81b8/SpaceSyntax-in-Architectural-Design.pdf [Accessed: 25 March 2019]

Edwards, J. R., Caplan, R. D., Van Harrison, R. (1998) "PersonEnvironment Fit Theory: Conceptual Foundations, Empirical Evidence, and Directions for Future Research", In: Cooper, C. L. (ed.) Theories of organizational stress, Oxford: Oxford University Press, Oxford, UK, pp. 28-67. [online] Available at: http://public.kenan-flagler.unc.edu/faculty/edwardsj/edwardsetal1998.pdf [Accessed: 25 March 2019]

Galindo, M. P., Hidalgo, M. C. (2005) "Aesthetic preferences and the attribution of meaning: Environmental categorization processes in the evaluation of urban scenes", International Journal of Psychology, 40(1), pp. 19-26.

https://doi.org/10.1080/00207590444000104

Haq, S., Girotto, S. (2003) "Ability and intelligibility: Wayfinding and environmental cognition in the designed", In: 4th international space syntax symposium, London, UK, pp. 68.1-68.20. [online] Available at: https://www.researchgate.net/profile/ Saif_Haq/publication/228777461_Ability_and_intelligibility_ Wayfinding_and_environmental_cognition_in_the_designed/ links/55707a3808ae193af4200135.pdf [Accessed: 29 March 2019]

Haq, S., Luo, Y. (2012) "Space Syntax in Healthcare Facilities Research: A Review", HERD: Health Environments Research \& Design Journal, 5(4), pp. 98-117. https://doi.org/10.1177/193758671200500409

Hillier, B (1996) "Space is the Machine: A Configurational Theory of Architecture", Cambridge University Press, Cambridge, UK.

Hillier, B., Hanson J. (1984) "The social logic of space", Cambridge University Press, Cambridge, UK. https://doi.org/10.1017/CBO9780511597237

Hillier, B, Penn, A (1991) "Visible Colleges: Structure and Randomness in the Place of Discovery", Science in Context, 4(1), pp. 23-50. https://doi.org/10.1017/S0269889700000144

Hillier, B., Tzortzi, K. (2006) "Space Syntax: The Language of Museum Space", In: Macdonald, S. (ed.) A companion to museum studies, Wiley-Blackwell, Hoboken, NJ, USA, pp. 282-301.

Jiang, B., Claramunt, C. (2002) "Integration of Space Syntax into GIS: New Perspectives for Urban Morphology", Transactions in GIS, 6(3), pp. 295-309.

https://doi.org/10.1111/1467-9671.00112

Kádár, B. (2013) "Differences in the spatial patterns of urban tourism in Vienna and Prague", Urbani izziv, 24(2), pp. 96-111. [online] Available at: http://urbani-izziv.uirs.si/Portals/uizziv/papers/urbani-izziv-en-2013-24-02-002.pdf [Accessed: 25 March 2019]

Kahana, E., Lovegreen, L., Kahana, B., Kahana, M. (2003) "Person, Environment, and Person-Environment Fit as Influences on Residential Satisfaction of Elders", Environment and Behaviour, 35(3), pp. 434-453. https://doi.org/10.1177/0013916503035003007
Kaplan, S. (1983) "A Model of Person-Environment Compatibility", Environment and Behavior", 15(3), pp. 311-332. https://doi.org/10.1177/0013916583153003

Kaplan, S., Kaplan, R. (1982) "Cognition and environment: Functioning in an Uncertain World", Praeger, New York, USA.

Keskin, Z., Chen, Y., Fotios, S. (2015) "Daylight And Seating Preference In Open-Plan Library Spaces", International Journal of Sustainable Lighting, 17, pp. 12-20. https://doi.org/10.26607/ijsl.v17i0.12

Kupritz, V. W. (2003) "Accommodating Privacy to Facilitate New Ways of Working", Journal of Architecture and Planning Research, 20(2), pp. 122-135.

Losonczi, A., Halász, B., Keszei, B., Dobszai, D., Dúll, A. (2017) "Investigating changes in space usage preferences by changing aesthetic environmental variables", In: Heitor, T., Serra, M., Silva, J. P., Bacharel, M., da Silva, L. C. (eds.) Proceedings of the 11th Space Syntax Symposium. Instituto Superior Técnico, Departamento de Engenharia Civil, Arquitetura e Georrecursos, Portugal. pp. 131.1-131.16. [online] Available at: http://www.11ssslisbon.pt/ docs/book-proceedings-28092017.pdf [Accessed: 25 March 2019]

Montello, D. R. (2007) "The contribution of space syntax to a comprehensive theory of environmental psychology", In: Proceedings of the 6th International Space Syntax Symposium, Istanbul, Turkey, iv-1-iv-12. [online] Available at: https://pdfs.semanticscholar.org/ 5fa7/7d18672ef3b614a307cb71fe30bcd57dab59.pdf [Accessed: 25 March 2019]

Mumcu, S., Düzenli, T., Özbilen, A. (2010) "Prospect and refuge as the predictors of preferences for seating areas", Scientific Research and Essays, 5(11), pp. 1223-1233. [online] Available at: http://www. academicjournals.org/app/webroot/article/article1380536322_ Mumcu\%20et\%20al.pdf [Accessed: 25 March 2019]

Ng, C. F. (2016) "Behavioral Mapping and Tracking", In: Gifford, R. (ed.) Research methods for environmental psychology, John Wiley \& Sons, Chichester, West Sussex, UK, pp. 29-52. https://doi.org/10.1002/9781119162124.ch3

Ostroff, C., Schulte, M. (2007) "Multiple perspectives of fit in organizations across levels of analysis", In: Ostroff, C. L., Judge, T. A. (eds.) Perspectives on organizational fit, Psychology Press, Palmeira Mansions, Brighton, UK.

Ostwald, M. J., Dawes, M. (2013) "Prospect-refuge patterns in Frank Lloyd Wright's Prairie houses: Using isovist fields to examine the evidence", The Journal of Space Syntax, 4(1), pp. 136-159. [online] Available at: https://pdfs.semanticscholar.org/bd5e/ d43c934040c8f3d9b4e3b22394fca6375c3f.pdf [Accessed: 25 March 2019]

Peponis, J (1985) "The Spatial Culture of Factories", Human Relations, 38(4), pp. 357-390. https://doi.org/10.1177/001872678503800405

Peponis, J., Ross, C., Rashid, M. (1997) “The structure of urban space, movement and co-presence: The case of Atlanta", Geoforum, 28(34), pp. 341-358. https://doi.org/10.1016/S0016-7185(97)00016-X 
Peponis, J., Zimring, C., Choi, Y. K. (1990) "Finding the Building in Wayfinding", Environment and Behavior, 22(5), pp. 555-590. https://doi.org/10.1177/0013916590225001

Psathiti, C., Sailer, K. (2017) "A Prospect-Refuge Approach to Seat Preference: Environmental Psychology and Spatial Layout", In: Proceedings of the 11th International Space Syntax Symposium, 11, pp. 137.1-137.16. [online] Available at: http://www.11ssslisbon. pt/docs/proceedings/papers/137.pdf [Accessed: 29 March 2019]

Raford, N., Chiaradia, A., Gil, J. (2007) "Space Syntax: The Role of Urban Form in Cyclist Route Choice in Central London", In: TRB 86th Annual Meeting Compendium of Papers CD-ROM, Washington, DC, USA. [online] Available at: https://cloudfront. escholarship.org/dist/prd/content/qt8qz8m4fz/qt8qz8m4fz.pdf [Accessed: 25 March 2019]

Sussman, R. (2016) "Observational Methods: The First Step in Science", In: Gifford, R. (ed.) Research methods for environmental psychology, John Wiley \& Sons, Chichester, West Sussex, UK, pp. 9-27. https://doi.org/10.1002/9781119162124.ch2
Turner, A. (2004) "Depthmap 4: a researcher's handbook", Bartlett School of Graduate Studies, London, UK. [online] Available at: http://discovery.ucl.ac.uk/2651/1/2651.pdf [Accessed: 29 March 2019]

Ulrich, R. S. (1983) "Aesthetic and affective response to natural environment", In: Altman, I., Wohlwill, J. F. (eds.) Behavior and the Natural Environment, Human Behavior and Environment (Advances in Theory and Research), Vol 6, Springer, Boston, MA, Springer, Boston, MA, USA. pp. 85-125.

https://doi.org/10.1007/978-1-4613-3539-9_4

Varoudis, T., Psarra, S. (2014) "Beyond two dimensions: Architecture through-three dimensional visibility graph analysis", The Journal of Space Syntax, 5(1), pp. 91-108. [online] Available at: http://discovery.ucl.ac.uk/1477266/1/Psarra_200-1300-1-PB.pdf [Accessed: 25 March 2019] 